\title{
Classification of Enchepalo Graph (EEG) Signals For Epilepsy Using Discreate Wavelet Transform and K-Nearest Neighbor Methods
}

\author{
Maulana Angga Pribadi \\ \{maulanaanggapribadi@gmail.com\}
}

Program Studi Informatika, Fakultas Sains dan Teknologi, Universitas Muhammadiyah Sidoarjo

\begin{abstract}
Epileps is a disorder of the contents of the nervous system of the human brain resulting in the presence of abnormal activity that is the excessive activity of neuron cells in the brain. In Indonesia there are more than 1,400,000 cases of Epilepsy each year with 70,000 additional cases each year. About 4050\% occurs in children. A widely used method for assessing brain activity is through a sephalogram (EEG) Electrone signal. The Epilepsy classification system is built with extraction and identifikas stages. Wavelet exctraction is suitable for non-stationary signal analysis such as EEG signals. Wavelet tranformation can extract signal components only at the required frequency. So that it can also reduce the amount of data but without losing meaningful information. But to make it work and can be used on a system needs to be done classification in order to be able to distinguish between commands from each other. So it is used K-Nearest Neighbour $(K-N N)$ classification method so that the signal that has been eliminated buzz can be directly entered into the classification to determine the correct wrongness of a data. In this study obtained the results of data accuracy value that $K=1$ has the largest percent of $100 \%$ and the smallest percent is found in $K=7$ and $K=11$ namely $14.2 \%$ and $18.2 \%$ it is caused by the presence of classes that do not match the test data so as to reduce the percentage of akurai in the $K$.
\end{abstract}

Keywords - Epilepsy; Discrete Wavelet Transform (DWT); Enchepalo Graph (EEG SIGNAL); K-Nearest Neighbors $(K N N)$

Abstrak. Epilepsi adalah gangguan pada isi sistem saraf otak manusia yang mengakibatkan adanya aktivitas yang tidak normal yaitu aktivitas berlebihan dari sel neuron pada otak. Di Indonesia terdapat lebih dari 1.400 .000 kasus Epilepsi setiap tahun dengan 70.000 pertambahan kasus setiap tahunnya. Sekitar 4050\% terjadi pada anak-anak. Metode yang banyak digunakan untuk menilai aktivitas otak adalah melalui sinyal Elektrone sephalogram (EEG). Sistem klasifikasi Epilepsi dibangun dengan tahap ekstraksi dan identifikas.Ekstraksi wavelet sangat cocok digunakan untuk melakukan analisis sinyal non stasioner seperti sinyal EEG. Tranformasi wavelet dapat mengekstraksi komponen-komponen sinyal hanya pada frekuensi yang diperlukan. Sehingga dapat mereduksi pula jumlah data namun tanpa kehilangan informasi yang berarti. Namun untuk membuatnya bisa bekerja dan bisa dipakai pada sebuah sistem perlu dilakukan klasifikasi agar dapat bisa membedakan antara perintah satu dengan yang lainnya. Maka digunakanlah metode klasifikasi K-Nearest Neighbour (K-NN) agar sinyal yang sudah dihilangkan dengungan bisa langsung masuk kedalam klasifikasi untuk ditentukan benar salahnya sebuah data tersebut. Pada penelitian ini didapatkan hasil nilai akurasi data bahwa $\mathrm{K}=1$ memiliki persen terbesar yakni 100\% dan persen terkecil terdapat pada $K=7$ dan $K=11$ yakni 14,2\% dan 18,2\% hal tersebut disebabkan karena adanya kelas yang tidak sesuai dengan data uji sehingga dapat mengurangi persentasi dari akurai pada K tersebut.

Kata kunci - Epilepsi; Discrete Wavelet Transform (DWT) Enchepalo Graph (EEG SIGNAL); K-Nearest Neighbours (KNN)

\section{Pendahuluan}

Epilepsi adalah gangguan pada sistem saraf otak manusia yang mengakibatkan adanya aktivitas yang tidak normal yaitu aktivitas berlebihan dari sel neuron pada otak. Aktivitas dari neuron yang berlebihan akan menimbulkan dampak seperti melamun sesaat, kejang-kejang, gangguan kesadaran, kontraksi otot, serta kesemutan. Epilepsi adalah gangguan neurologis kedua yang paling umum pada manusia setelah stroke. Sekitar 40 atau 50 juta orang di dunia menderita epilepsi [1]. Electroencephalogram (EEG) merupakan alat yang digunakan sebagai test untuk mendeteksi adanya kelainan pada aktivitas sinyal otak [2]. Metode yang banyak digunakan untuk menilai aktivitas otak adalah melalui sinyal Elektroensephalogram (EEG). Ketika sinyal EEG direkam dan ditampilkan dalam suatu software yang terkandung didalamnya tidak hanya sinyal otaknya saja ada beberapa sinyal yang berasal dari tubuh manusia oleh karena itu dibutuhkan suatu metode yang dapat mengurangi suara atau sinyal bising tersebut. Discreate Wavelet Transform (DWT) adalah suatu metode yang dapat mengurangi suara atau signal bising (denoise) dengan begitu sinyal yang terdapat banyak sekali noise dapat dinetralisir dengan memakai metode DWT ini sehingga menjadi jernih. Tetapi metode DWT hanya berfungsi untuk denoising sinyal tidak untuk melakukan klasifikasi sebagai hasil akhir, maka dengan begitu dipilihlah metode $K$-Nearest Neighbours (KNN) sebagai metode klasifikasi sinyal untuk mengelola data yang benar agar diperoleh hasil yang maksimal. Berdasarkan masalah diatas, maka akan dikembangkan aplikasi yang berjudul "Klasifikasi Sinyal Enchepalo Graph (EEG) Untuk Gangguan Penyakit Epilepsi Dengan Menggunakan Metode Discreate Wavelet Transform Dan K-Nearest Neighbor". 


\section{METODE}

\section{A. Sinyal}

Sinyal merupakan sebuah fungsi yang bertugas menyampaikan informasi mengenai tingkah laku atau atribut dari beberapa fenomena. Sinyal juga dapat didefinisikan sebaga perubahani yangi dapati diamatii dalami entitasi yangi masihi bisai dihitungi [3]. Sinyal dapat dikonversi menjadi sinyal elektronik oleh berbagai sensor. Beberapa contoh sinyal adalah:

1. Suara

Suara adalah getaran medium, sinyal suara menghubungkan nilai tekanan ke setiap nilai waktu dan ruang.

2. Gambar

Gambar tersiri dari kecerahan atau sinyal warna. Penampilan gambar disajikan sebagai gelombang elektromagnetik yang dipancarkan atau dipantulkan.

3. Video

Sinyal video adalah urutan gambar. Suatu titik dalam sebuah video diidentifikasikan oleh posisi dua dimensi.

4. Gerak

Gerakan sebuah benda dapat dianggap sebagai sinyal, dan dapat dimonitor oleh berbagai sensor untuk memberikan sinyal listrik. Sebagai contoh, radar dapat memberikan sinyal elektromagnetik untuk gerakan.sebuah pesawat.

\section{B. Electro encephalo graph}

Electro Encephalo Graph atau yang biasa disebut dengan EEG merupakan sinyal amplitude rendah yang dihasilkan di otak karena komunikasi yang terjadi antara sejumlah besar neuron satu sama lain. Komunikasi yang terjadi antar neuron ini menghasilkan sinyal listrik yang sangat kecil. Oleh karena itu, Electro Enchepalo Graph sinyal pengukur aktivitas listrik yang nantinya dapat digunakan untuk memeriksa perilaku manusia [4]. EEG digunakan untuk merekam aktivitas listrik otak, dengan cara menempatkan elektroda di sepanjang kulit kepala. EEG mengukur fluktuasi tegangan yang dihasilkan dari arus ion pada neuron otak. Dalam konteks klinis, EEG mengacu pada perekaman aktivitas listrik spontan otak selama periode waktu tertentu dan tercatat dari beberapa elektroda yang ditempatkan pada kulit kepala [5]. EEG sering digunakan untuk proses diagnosa, seperti mendiagnosa penyakit epilepsi, gangguan tidur, tumor, stroke, kematian otak dan gangguan otak lainnya. EEG digunakan untuk merekam aktivitas listrik otak, dengan cara menempatkan elektroda di sepanjang kulit kepala. EEG sering digunakan untuk proses diagnosa, seperti mendiagnosa penyakit eplilepsi, gangguan tidur, tumor, stroke, kematian otak dan gangguan otak lainnya.

\section{Data sinyal EEG dari Universitas Bonn}

Data sinyal EEG dari Universitas Bonn terdiri atas lima kelas dataset yaitu A, B, C, D, dan E. Tiap dataset berisi 100 segmen EEG saluran tunggal dengan durasi selama 23.6 detik. Setiap segmen dipilih dan dipotong dari rekaman EEG multi channel secara kontinyu setelah inspeksi artefak secara visual, misalnya gerakan mata atau aktivitas otot. Set A dan B adalah sinyal yang diambil dari rekaman EEG yang dilakukan pada lima sukarelawan sehat dengan skema penempatan elektroda standar (International 10-20 system). Relawan dalam kondisi santai dan terjaga dengan mata terbuka (untuk set A) dan mata tertutup (untuk set B). Set C - E berasal dari arsip EEG diagnosis presurgical. EEG dari lima pasien dipilih, dan semua telah mencapai kontrol kejang yang lengkap, setelah reseksi dari salah satu formasi hippocampal, sehingga didiagnosis dengan benar masuk zona epileptogenic. Sinyal set Di direkam saat zona epileptogenic, dan berada pada interval tanpa kejang dan set $\mathrm{C}$ berasal dari pembentukan hippocampus pada belahan yang berlawanan dari otak. Sementara set $\mathrm{C}$ dan Di berisi aktivitas yang hanya diukur selama interval tanpa kejang, sedangkan set $\mathrm{E}$ hanya berisi aktivitas kejang. Data set A dan set D tersebut yang digunakan dalam penelitian ini. Sesuai dengan referensi yang ada, semua sinyal EEG direkam dengan sistem amplifier dengan kanal 128.

\section{Epilepsi}

Epilepsi merupakan penyakit saraf yang ditandai dengan episode kejang yang dapat disertai hilangnya kesadaran penderita. Meskipun biasanya disertai hilangnya kesadaran, ada beberapa jenis kejang tanpa hilangnya kesadaran. Penyakit ini disebabkan oleh ketidakstabilan muatan listrik pada otak yang selanjutnya mengganggu koordinasi otot dan bermanifestasi pada kekakuan otot atau pun hentakan repetitif pada otot. Faktor resiko epilepsi antara lain asfiksia neonatorium, riwayat demam tinggi, riwayat ibu yang memiliki faktor resiko tinggi (wanita dengan latar belakang susah melahirkan atau pengguna obat-obatan, hipertensi), pasca trauma kelahiran, riwayat ibu yang menggunakan obat anti konvulsan selama kehamilan, riwayat intoksikasi obat-obatan maupun alkohol, adanya riwayat penyakit pada masa anak-anak (campak, mumps), riwayat gangguan metabolisme nutrisi dan gizi, riwayat keturunan epilepsi. 


\section{E. Discreate wavelet transform}

Discrete Wavelet Transform (DWT) adalah sebuah teknik matematis yang digunakan untuk penyaringan Noise, Reduksi data, dan Deteksi Singularitis, yang membuatnya menjadi pilihan terbaik dalam pemrosesan data dengan deretan waktu. Discrete Wavelet Transform ini telah ada sejak 100 tahun yang lalu, dan telah digunakan secara luas dalam berbagai bidang seperti pemrosesan sinyal dan khususnya sering digunakan dalam penelitian kompresi sinyal, peningkatan gambar dan pengurangan noise [6]. Transformasi wavelet diskrit mengubah deret waktu menggunakan serangkaian fungsi dasar yang disebut wavelet. Tujuan transformasi adalah untuk mengurangi ukuran data dan / atau mengurangi noise. Dengan nama, wavelet berarti gelombang kecil [7]. Transformasi wavelet diskrit mengubah deret waktu menggunakan serangkaian fungsi dasar yang disebut wavelet. Tujuan transformasi adalah untuk mengurangi ukuran data dan / atau mengurangi noise. Maka perhitungannya digunakanlah rumus untuk mencari Low dan High sinyal.

$$
\operatorname{yhigh}[n]=\sum_{k=\infty}^{\infty} x[k] h[2 n-k] \text { i ylow }[n]=\sum_{k=\infty}^{\infty} x[k] g[2 n-k]
$$

Karena fungsi utama Discrete Wavelet Transform adalah menghilangkan suara bising dari artefak otot, okular, dan jantung serta menguraikan sinyal EEG menjadi perkiraan koefisien frekuensi rendah dan koefisien detail frekuensi tinggi Akibatnya, sinyal dengan energi tinggi terkonsentrasi dikoefisien wavelet tertentu. Sebaliknya, distribusi energi kebisingan tidak berubah yang berarti energinya tidak dipertahankan oleh koefisien yang besar. Jadi, rekonstruksi parsial sinyal EEG dilakukan dengan menerapkan wavelet terbalik hanya mengubah pada koefisien di mana konsentrasi energi sangat tinggi. Dengan demikian, sinyal EEG dinolkan menggunakan DWT [8].

\section{F. K-nearest neighbor}

K-Nearest Neighbor adalah suatu metode yang digunakan untuk melakukan klasifikasi terhadap suatu objek, berdasarkan data yang memiliki jarak terdekat dengan suatu objek tersebut, sesuai dengan jumlah tetangga terdekatnya yang bernilai k. Jauh dekatnya tetangga, biasanya dihitung berdasarkan jarak Euclidean. Jauh dekatnya tetangga, biasanya dihitung berdasarkan jarak Euclidean dengan menggunakan persamaan sebagai berikut:

$$
d(x-y)=\sqrt{\sum_{j=1}^{n}\left(X_{j}-Y_{j}\right)^{2}}
$$

Dengan :

$\mathrm{D}$ : jarak data uji ke data pembelajaran

$\mathrm{Xj}$ : data uji ke $-\mathrm{j}$ dengan $\mathrm{j}=1,, 2, \ldots \mathrm{n}$.

$\mathrm{Yj}$ : data belajar $\mathrm{ke}-\mathrm{j}=1,2 . . \mathrm{n}$

\section{G. MATLAB}

MATLAB adalah platform pemrograman yang dirancang khusus untuk para insinyur dan ilmuwan. Jantung dari MATLAB adalah Bahasa MATLAB, Bahasa yang berbasis matriks yang memungkinkan ekspresi matematis komputasi yang paling alami. MATLAB menggabungkan lingkungan desktop yang disesuaikan untuk analisis iterative dan proses desain dengan Bahasa pemrograman yang mengekspresikan matriks dan matematika array secara langsung [9]. Jutaan insinyur dan ilmuwan di industri dan akademisi menggunakan MATLAB. MATLAB dapat digunakan untuk menganalisis data, mengembangkan algoritma, dan pembuatan model dan berbagai aplikasi, termasuk pembelajaran mendalam dan pembelejaran mesin, pemrosesan sinyal dan komunikasi, pemrosesan gambar dan video, sistem kontrol, pengujian dan pengukuran, keuangan komptasional, dan biologi komputasi. Fungsi Bahasa, aplikasi dan matematika memungkinkan untuk cepat menjelajahi berbagai pendekatan untuk mendapatkan solusi.

\section{H. GUI designer (GUIDE)}

GUI (juga dikenal sebagai antarmuka pengguna grafis atau UI) meyediakan kontrol aplikasi perangkat lunak, yang menghilangkan kebutuhan untuk mempelajari bahasa atau jenis perintah untuk menjalankan aplikasi [10]. MATLAB aplikasi mandiri program MATLAB dengan GUI depan berakhir yang mengotomatisasi tugas atau perhitungan. GUI biasanya berisi kontrol seperti menu, toolbar, tombol, dan slider. Banyak produk MATLAB, seperti Curve Fitting Toolbox, Signal Processing Toolbox, dan Control System Toolbox termasuk aplikasi dengan antarmuka pengguna khusus. 


\section{Hasil dan Pembahasan}

\section{A. Hasil pengujian}

Dari 5 class data dipilihlah Class A dan Class D dengan 30 data Training dan 10 data Testing dari masingmasing kelas yang diproses kedalam DWT untuk dilakukan proses denoising sinyal atau proses penjernihan sinyal yang dibagai kedalam 3 level penjernihan dimana pada awalnya sinyal memiliki noise yang cukup banyak akan dikurangi di level 1 dengan mencabangkan sinyalnya menjadi High pass sinyal (HpsA) dan Low pass sinyal (LpsB) lalu kemudian noise yang masih tertinggal di level 1 dimana sinyal sudah terpisah menjadi high pass dan low pass akan akan dijernihkan lagi di level 2 menjadi 4 cabang yang membagi (HpsA) menjadi (HpsA.1 dan LpsA.2) dan (LpsB menjadi HpsB.3 dan LpsB.4) kemudian dilevel 3 dijernihkan atau di denoise lagi dan di decompose menjadi 8 cabang yakni (HpsA.1 menjadi HpSA.1.A dan LpsA.1.B) lalu (LpsA.2 menjadi LpsA.2.C dan Lps A.2.D) lalu (HpsB.3 menjadi HpsB.3.E dan LpsB.4.F) dan (LpsB.4 menjadi LpsB.4.G dan LPSB.4.H).

\section{B. Pembahasan}

Metode discreate walvet transform (DWT)

Metode Discreate Wavelet Transform (DWT) adalah metode mendenoising dan mendekomposisi signal menjadi beberapa level tergantung yang peneliti inginkan. Data yang sudah di dapatkan tadi akan diambil 2 kelas yakni dataset A untuk data normal dani dataset D untuk data epilepsi. Masing-masing data sinyal EEG digital tersebut terdiri atas 4097 data diskrit, dan diambilah 30 data pada dataset A dan dataset D untuk dilakukan ekstrasi DWT dan mengambil ciri ekstraksi berupa Energi sebagai contoh perhitungannya digunakanlah rumus untuk mencari Low dan High sinyal. Berikut adalah contoh perhitungan yang merujuk pada rumus 2.1 :

Tabel 2. Ekstraksi ciri dari data normal kelas A

\begin{tabular}{cllllllll}
\hline No & Energy1 & Energy2 & Energy3 & Energy4 & Energy5 & Energy6 & Energy7 & Energy8 \\
\hline 1 & 6798682 & 5294377.3 & 628882 & 1528020.8 & 251063.25 & 5294377.3 & 377818.75 & 1528020.8 \\
2 & 8719758.3 & 6882808.1 & 808726.25 & 1863846.1 & 306031.63 & 6882808.1 & 502694.63 & 1863846.1 \\
3 & 8532665.5 & 6687823.8 & 780789.5 & 1845997.8 & 301121.25 & 6687823.8 & 479668.25 & 1845997.8 \\
4 & 7948764.8 & 1164104.8 & 378544.13 & 785560.63 & 5694608.1 & 2259632.6 & 5694608.1 & 2259632.6 \\
5 & 3976948.5 & 3472229.5 & 259419.5 & 504915 & 94771 & 3472229.5 & 164648.5 & 504915 \\
6 & 6256025.3 & 5434444.6 & 397536.25 & 823344.63 & 146900.13 & 5434444.6 & 250636.13 & 823344.63 \\
7 & 4222725 & 3576220.5 & 273145 & 654968.5 & 119220 & 3576220.5 & 153925 & 654968.5 \\
8 & 2881585.3 & 2484184.9 & 234330.25 & 397544.38 & 66704.375 & 2484184.9 & 167625.88 & 397544.38 \\
9 & 3613386.3 & 3125649.9 & 251089.25 & 492636.38 & 92152.375 & 3125649.9 & 158936.88 & 492636.38 \\
10 & 3898650.8 & 3362546.4 & 249030.75 & 537128.38 & 93669.375 & 3362546.4 & 155361.38 & 537128.38 \\
\hline
\end{tabular}

Dari 60 data training yang berasal dari data normal kelas A dan data epilepsi kelas D dengan 30 data dimasingmasing kelas, serta juga 20 data testing yang berasal dari 10 data di masing-masing data normal kelas A dan data epilepsi di ekstraksi lewat sebuah program GUI MATLAB seperti yang tertera pada tabel 2 sehingga didapatkan lah nilai decomposisi level 1, level 2, dan level 3 lalu dari decomposisi level 3 diambillah ekstraksi ciri berupa Energi seperti gambar 1 bagian kanan, data tersebutlah yang akan digunakan dalam klasifikasi K-Nearest Neighbours.

\section{Metode k-nearest neighbor}

K-Nearest Neighbours adalah metode pengklasifikasian data dengan mencari nilai terdekat dari nilai $\mathrm{K}$ itu sendiri. Karena metode ini bekerja melalui jarak terdekat maka rumus jarak Euclidiean Distance digunakan sebelum mencari nilai dari K itu sendiri. Setelah nilai Euclidean Distance yang menggunakan perhitungan antara data Training dan data Testing didapatkan maka langkah selanjutnya adalah menentukan nilai dari K tersebut dan dalam penenlitian ini nilai $\mathrm{K}$ yang dicari yakni $\mathrm{K}=1, \mathrm{~K}=3, \mathrm{~K}=5, \mathrm{~K}=7, \mathrm{~K}=11, \mathrm{~K}=13$, dani $\mathrm{K}=15$. Dalam melakukan Klasifikasi K-NN data Energi yang diambil dari decomposisi level 3 yang sudah didapat pada masing masing data testing dan data Training dilakukan perhitungan dengan cara satu baris data testing dari suatu kelas di hitung dengan setiap baris dari data training yang berasal dari setiap kelas, karena terdapat total 60 data Training maka untuk setiap Euclidean Distance pada data Testing yang berjumlah 10 data. Dengan begitu didapatkanlah 60 data dimana terdapat 30 data normal kelas A dan 30 data epilepsi kelas D. Namun untuk setiap baris yang memiliki data Euclidean 
Distance sebanyak 60 data perlu dilakukan pengurutkan data dari yang data terkecil ke yang data terbesar dengan begitu dapat mempermudah pengambilan nilai $\mathrm{K}$ yang dilakukan secara manual lewat microsoft Excel. Berikut adalah contoh perhitungan yang merujuk pada rumus 2 :

Tabel 3. Euclidean Distance dari data normal kelas A

\begin{tabular}{|c|c|c|c|c|}
\hline No & Euclidean Distance & Kelas & Disortir kelas & \\
\hline 1 & 22068668.65 & 1 & 665228.10 & 2 \\
\hline 2 & 39075663.51 & 1 & 844960.46 & 2 \\
\hline 3 & 43217802.35 & 1 & 1582030.20 & 2 \\
\hline$\ldots$ & $\ldots \ldots$ & $\ldots \ldots$ & $\ldots \ldots$ & ....... \\
\hline 60 & 844960.463 & 4 & 1277807907.86 & 1 \\
\hline
\end{tabular}

Dari data hasil perhitungan data Training dan data Testing didapatlah hasil seperti tabel 3 dimana setiap baris data Testing menghasilkan 60 nilai Euclidean Distance karena didalamnya terdapat 2 Class yang masing masing kelas memiliki 30 Data Training. Untuk satu kelas data Testing didapatlah 600 data Euclidean Distance yang berisi data normal kelas A dan data epilepsi. Data hasil equlidian distance tersebut barulah dilakukan pensortiran dari nilai terkecil ke terbesar agar data tersebut bisa memudahkan dalam pencarian nilai $\mathrm{K}$.

Tabel 4. Nilai K

\begin{tabular}{c|ccccccc}
\hline No & $\mathrm{K}=1$ & $\mathrm{~K}=3$ & $\mathrm{~K}=5$ & $\mathrm{~K}=7$ & $\mathrm{~K}=11$ & $\mathrm{~K}=13$ & $\mathrm{~K}=15$ \\
\hline 1 & 2 & 2 & 2 & 2 & 2 & 2 & 2 \\
2 & & 2 & 2 & 2 & 2 & 2 & 2 \\
3 & 2 & 2 & 2 & 2 & 2 & 2 \\
4 & & 2 & 2 & 2 & 2 & 2 \\
5 & & 2 & 2 & 2 & 2 & 2 \\
6 & & & 1 & 1 & 1 & 1 \\
7 & & & 2 & 2 & 2 \\
8 & & & & 2 & 2 & 2 \\
9 & & & & 2 & 2 & 2 \\
10 & & & & 2 & 2 & 2 \\
11 & & & & & 2 & 2 \\
13 & & & & & & 2 \\
15 & & & & & & \\
\end{tabular}

Pada Tabel 4 nilai K terlebih dahulu haruslah ditentukan sebelum mengklasifikasikannya, disini nilai ditentukan dengan menggunakan angka ganjil agar kepastian dalam menentukan langkah selanjutnya tidak membingungkan.

Tabel 5. Hasil nilai Akurasi K-Nearest Neighbor

\begin{tabular}{lllllllll}
\hline Data Uji Class & & $\mathrm{K}=1$ & $\mathrm{~K}=3$ & $\mathrm{~K}=5$ & $\mathrm{~K}=7$ & $\mathrm{~K}=11$ & $\mathrm{~K}=13$ & $\mathrm{~K}=15$ \\
\hline Persentase & $\begin{array}{l}\text { Data } \\
\text { Epilepsi }\end{array}$ & $100 \%$ & $100 \%$ & $100 \%$ & $14,2 \%$ & $18,2 \%$ & $23,1 \%$ & $23,1 \%$
\end{tabular}


Procedia of Engineering and Life Science Vol.1 No. 1 March 2021

Seminar Nasional \& Call for Paper Fakultas Sains dan Teknologi (SENASAINS $1^{\text {st }}$ )

Universitas Muhammadiyah Sidoarjo

$\begin{array}{lllllllll}\text { Persentase } & \begin{array}{l}\text { Data } \\ \text { Normal }\end{array} & 100 \% & 100 \% & 100 \% & 85,7 \% & 81,8 \% & 76,9 \% & 80 \%\end{array}$

Dari tabel diatas dapat diperoleh persentase K- Nearest Neigbor dari data epilepsi dan data normal. Tabel diatas dapat dihitung menggunakan rumus dibawah ini:

$$
\text { Akurasi }=\frac{\text { Banyak Data }}{\text { Nilai } K} \times 100 \%
$$

Dari contoh pada tabel 4 dapat juga ditarik sebuah kesimpulan mengenai seberapa besar akurasi yang bisa didapatkan dengan menggunakan klasifikasi data KNN, namun untuk memastikan nilai akurasinya maka terlebih dahulu perlu dilakukan perhitungan nilai K yang didominasi pada setiap data uji yang ada dapat dilihat pada tabel 4 dari $\mathrm{K}=1$ hanya memiliki 1 nilai yang sudah bisa dipastikan akurasinya adalah $100 \%$ karena akurasi memiliki persamaan dengan rumus peluang yakni munculnya 1 Class yang bernar dari $\mathrm{K}=1$ dengan begitu maka didapatlah sebuah kesimpulan dari $\mathrm{K}=1$ hinggai $\mathrm{K}=15$. Banyaknya data training dan testing pada suatu klasifikasi juga sangat mempengaruhi nilai dari persentasi dari klasifikasi KNN karena sebab itu dianjurkan untuk penelitan selanjut agar lebih menambah data training dan data testing agar hasil dari klasifikasi dan persentasi nilai dari $\mathrm{K}$ juga meningkat.

\section{KESIMPULAN}

Hasil Penelitian yang sudah dilakukan, peniliti memperkenalkan Sinyal Electroencephalography (Sinyali EEG) sebagai objek penelitian yang kemudian diekstraksi dengan dua metode Discrete Wavelet Transform (DWT) dan KNearest Neightbours $(K N N)$ dengan memakai sebuah ciri ekstraksi energi. Plot potongan sinyal EEG set A diambil 30 data untuk data training dan 10 data untuk data testing. Set Di diambil 30 data untuk data training dan 10 data untuk data testing. Setelah itu dilakukan proses ekstraksi DWT dan klasifikasi KNN sehingga data uji bisa dikategorikan termasuk data dalam kelasnya atau tidak, lalu dari proses pengambilan nilai dari $\mathrm{K}$ terdekat, lalu dari proses pengambilan nilai dari $\mathrm{K}$ terdekat juga didapatkan akurasi data bahwa $\mathrm{K}=1$ memiliki persen terbesar yakni $100 \%$ dan persen terkecil terdapat pada $\mathrm{K}=7$ dan $\mathrm{K}=11$ yakni $14,2 \%$ dan 18,2\% hal tersebut disebabkan karena adanya kelas yang tidak sesuai dengan data uji sehingga dapat mengurangi persentasi dari akurat pada $\mathrm{K}$ tersebut. Dalam akurasi banyaknya data Training mempengaruhi persentase ketepatan dalam mendapatkan data karena itu untuk penelitian dimasa depan peneliti bisa memperbanyak data trainning atau mengembangkan metodelogi agar hasil bisa semakin baik.

\section{UCAPAN TERIMA KASIH}

1. Ucapan terima kasih setulusnya kami ucapkan kepada kedua orangtua yang senantiasa mendoakan keberhasilan penulis, memberi semangat dan dukungan untuk segera menyelesaikan penulisan skripsi.

2. Dr. Hidayatullah, M.Si selaku Rektor Universitas Muhammadiyah Sidoarjo yang telah menyediakan fasilitas pada kegiatan perkuliahan.

3. Dr. Hindarto, S.Kom., M.T., selaku Dekan Fakultas Sains dan Teknologi Universitas Muhammadiyah Sidoarjo yang telah menyediakan fasilitas pada kegiatan perkuliahan.

4. Ir. Sumarno., MM., selaku Kaprodi Informatika yang telah menyediakan fasilitas dalam perkuliahan.

\section{REFERENSI}

[1] Eric R. Kandel, Larryi R.Squire. (2000). Neuroscience : Breaking Down Scientific Barries to the study of brain and mind. Journal Science. 290:1113-1120

[2] Campellone, JV (2006). Eeg Brain Wave Test di http://nlm.nih.gov/medlineplus/ency/article/0033931.html diakses pada tanggal 1 oktober 2016.

[3] Wikipedia. 2007. Signal di https://en.wikipedia.org/wiki/Signal. Diakses pada tanggal 23 Oktober 2018.

[4] Kumar, Sandeep. (2017). "EEGi Signali Classification Using PSO Trained RBF Neural Network for Epilepsy Identification.". Journal Informatics in Medicine Unlocked.

[5] Wikipedia. 2018. Electroencephalography di https://en.wikipedia.org/wiki/Electroenchepalography. Diakses pada tanggal 23 Oktober 2018 .

[6] Chaovalit,P., Gangopadhyay,A., Karabatis,G., \& Chen,Z.(2011). Discrete wavelet transform-based time series analysis and mining. ACM Computing Surveys, 43(2), 1-37. https://doi.org/10.1145/1883612.188363.

[7] Percival, Donald B; Walden, A. T. (2006). the Discrete Wavelet Transform and Consider, Inverse Tranform. Cambridge University Press. https://doi.org/https://doi.org/10.1017/CBO9780511841040. 
Procedia of Engineering and Life Science Vol.1 No. 1 March 2021

Seminar Nasional \& Call for Paper Fakultas Sains dan Teknologi (SENASAINS $1^{\text {st }}$ )

Universitas Muhammadiyah Sidoarjo

[8] Vasavi, K. P., Raju, P. R. S. S. V., Radhika, S., \& Prasad, G. D. K. (2016). A Mind Operated Computer Mouse Using Discrete Wavelet Transforms for Elderly People with Multiple Disabilities. Procedia Computer Science, 85(Cms), 166-175. https://doi.org/10.1016/j.procs.2016.05.205

[9] Mathworks. 1994. Whati isi MATLAB di https://www.mathworks.com/discovery/what-is matlab. Diakses pada Oktoberi 2018.

[10] Mathworks. 2007. Matlab GUI di https://ww2.mathworks.cn/en/discovery/matlab gui.html. Di akses pada tanggal 1 November 2018. 